\title{
Conhecimentos tradicionais, tradição e cultura: $O$ conhecer-fazer de plantas medicinais em Tupi I/Alto Solimões/Amazonas
}

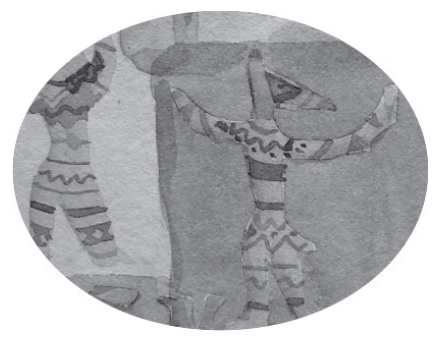

Priscila Freire Rodrigues*

Hiroshi Noda**

\section{Resumo}

A cultura dos povos tradicionais é muito importante para o processo da conservação do mundo natural. Neste artigo, a compreensão de uma construção específica do conhecimento é procurada por meio da análise do processo cultural de utilização das plantas medicinais por uma população humana em uma comunidade da região do Alto Rio Solimões, no Amazonas. Os resultados mostraram que o conhecimento tradicional é um "produto" da relação dialética se considerarmos uma conjuntura social e histórica.

Palavras-chave: Conhecimentos Tradicionais. Alto Solimões. Amazônia.

\begin{abstract}
The culture of the traditional peoples is very important to the process of the natural world conservation. In this article, the understanding of a specific

* Cientista Social, Mestre em Ciências do Ambiente e Sustentabilidade na Amazônia pela Universidade Federal do Amazonas/Ufam. Atualmente atua como professora substituta do Departamento de Ciências Sociais do Instituto de Ciências Humanas e Letras/DciS/ICHL/ Ufam. priscillafreyre@hotmail.com/92240659.

** Dr. em Ciências Agrárias, Pesquisador do Inpa, Departamento de Ciências Agronômicas, Programa de Melhoramento Genético de Hortaliças.
\end{abstract}


knowledge construction is searched by means of the analysis of the cultural process of medicinal plants utilization by a human population in a High River Solimões region community, in the Amazon. The results showed that the traditional knowledge is a "product" of the dialectic relation if considers a social and historical conjuncture.

Keywords: To know traditional. High Solimões. Amazônia.

\section{Introdução}

Questões em torno do etnoconhecimento buscam evidenciar a ciência como uma forma de conhecimento em relação com outras formas de perceber e explicar o mundo, de maneira que se ponha em análise a relação sociedade/ natureza na contemporaneidade. Dessa forma é importante analisar a validade do conhecimento científico do ponto de vista de um modo de conhecimento que precisa dialogar com os saberes locais para compreender a relação sociedade/ natureza na medida em que implicam na percepção, interação e apropriação do meio natural pelas populações humanas. Diante dessas questões, o objetivo desse artigo, ao caracterizar o uso, manejo e conservação de plantas medicinais a partir dos conhecimentos tradicionais, é evidenciar um processo ecológico e sociocultural da conservação no âmbito da dimensão reflexiva/prática na vida social de uma forma de conhecer singular histórica e culturalmente. Para tanto, o procedimento metodológico utilizado é pautado num ensaio etnográfico, privilegiando uma análise qualitativa dos dados empíricos, valorizando as falas dos sujeitos sociais de uma comunidade na região do Alto Solimões/Amazonas. Relacionamos os aspectos da vida social com questões em torno do processo de manejo e conservação das plantas medicinais de modo a ressaltar dois aspectos: um no que diz respeito ao conhecimento e manuseio do mundo natural e o outro no âmbito social evidenciando a estreita relação sociedade/ natureza no conhecimento e conservação de saberes sobre aquelas plantas.

\section{Tupi I e uma realidade amazônica: a localização do local e do lugar}

Não se sabe direito, mas “Tupi I já existe há 67 anos. Tupi II é terra firme, aqui era de restinga (terra mais alta do que a várzea, mas que ainda alaga) aí o 
pessoal foi saindo porque alagava, então foram indo pra lá"1 (Tupi II). "Em 1974 o irmão José (da Igreja Católica) passou colocando a cruz. Eles fizeram essa divisão de um e dois. Mas também dizem porque a maioria de Tupi II é da Cruzada, mas tem também da Católica e da Pentecostal lá. Esse nome... dizem que é porque tinha uma tribo que se chamava Tupi e aí ficou esse nome. Mas, ninguém sabe ao certo". Tem em registros históricos, que São Paulo de Olivença surgiu de uma das missões fundadas por Samuel Fritz, missionário da Companhia de Jesus, a serviço do governo espanhol, que se chamava São Paulo dos Apóstolos em 1689. Mas, em 1691 o governo português ordenou a expulsão dos jesuítas espanhóis que ainda relutaram pela permanência. Elevada à categoria de vila em 1759, a aldeia de São Paulo dos Cambebas; consta que oficialmente foi elevada em 1817 com o nome de Olivença e novamente em 1882, pela Lei n. ${ }^{\circ}$ 599 (ENCICLOPÉDIA DOS MUNICÍPIOS BRASILEIROS, 1957).

Sempre pelo rio, as estradas d'águas do Amazonas que levam e trazem navegantes de uma vida banzeirada, que o diga quem vai a Tupi I, pois, lentas são as horas mesmo que pareça que a paisagem esteja andando junto e rápido. Demora, mas chega. O município mais próximo de Tupi I é Tabatinga, cinco horas de pec-pec, depois Benjamin Constant, seis horas, mas pertence ao território de São Paulo de Olivença, o que demora umas doze horas de pec-pec, mas de motor mais rápido custa menos. A microrregião do Alto Solimões abrange uma área de 132.195 mil km², e o Município de São Paulo de Olivença tem uma área de 19.922,0 $\mathrm{Km}^{2}$ sendo que sua distância de Manaus, capital do Estado do Amazonas, em linha reta é de $988 \mathrm{~km}$ e por via fluvial $1.235 \mathrm{~km}$. A população total, de acordo com o senso de 2000, é de 22.994 habitantes, sendo na área urbana 8.654 e na área rural 14.340. A população indígena representa cerca de 33,58\% do total da população, composta por povos Tikuna e Kokama, principalmente. O acesso a Tupi I é via fluvial pelo rio Solimões. Do município de Tabatinga, que faz fronteira via fluvial e terrestre com a cidade de Letícia, Colômbia, corresponde entre quatro e sete horas de viagem, dependendo da potência do motor da embarcação. Do Município de Benjamin Constant, que faz fronteira via fluvial com o Peru, corresponde também em torno de cinco e sete horas, bem como, do Município de São Paulo de Olivença, sede distrital à qual pertence territorialmente Tupi I, porém é mais distante correspondendo a uma distância maior em horas, mais que sete horas dependendo do tipo de embarcação. Apesar de registros históricos citarem muitos povos indígenas naquela localidade, em Tupi I a presença de indígenas não é muito notável, 
sua população é predominantemente não indígena. Atualmente, registram-se 16 casas, mas não corresponde ao número de famílias, posto que seja comum a presença da família de filhos e filhas compartilhar a mesma moradia dos pais. A produção local baseia-se na agricultura e na pesca. Mas a agricultura é a principal atividade econômica de Tupi I/SPO. A plantação destinada ao consumo e venda é de banana, melancia e milho; quanto à produção destinada à venda é o pepino, verduras, pimentão, tomate e mamão e a mandioca. A pesca também é destinada para o consumo e venda; no entanto, a venda geralmente é em pouca proporção. As espécies mais citadas foram curimatã, pacu, sardinha, surubim, cascudinho, pirabutão, bodó e, ainda, pirarucu que são vendidas principalmente no município de Tabatinga pela maior proximidade.

À primeira vista a paisagem se revela rica em árvores frutíferas e de boa terra para se plantar. É váržea, mas há mais de três anos não alaga; seca cada vez mais; as praias que surgem no meio do rio completam a pintura do lugar que se move na moldura que não se enquadra.

Acorda-se cedo; algumas mulheres vão para a roça e outras para o porto lavar roupa ou lavar vasilhas. Alguns homens também vão para roça e outros, cedo já estão voltando da pesca trazendo sardinha, mais é sardinha que dá, para o café da manhã. Fazem a venda de peixe, mas é bem pouco. Antigamente dava toda qualidade de peixe. Mas agora tá ficando mais difícil o tambaqui. A perseguição foi demais. Tem uma ressaca grande (curva que fica na beira do barranco, devido o barro que cai, onde os peixes se aglomeram), mas o próprio pessoal não respeita, vai e pesca. Alguns têm canoa e rabeta e outros só a canoinha. Também se trabalha na agricultura, fazendo roça, para fazer farinha. A maioria do que se planta é só para o consumo, quando dá, depende um pouco da sorte. Todos da família participam e de maneira igual; as crianças sempre vão tanto para roça quanto para a pesca; para elas ao que parece não se trata de um momento estritamente de trabalho, mas também de um momento de diversão porque se encontram entre primos e primas, principalmente, na hora que dá pra brincar, pular n'água, essas coisas... A agricultura e a pesca constituem as atividades produtivas principais, mas, ao nível de maior atividade, a agricultura baseada na produção familiar é a atividade mais preponderante. A destinação da produção é sempre dividida entre o consumo e a venda que é realizada no município mais próximo. Quanto à pesca é uma atividade frequentemente realizada ao longo dos rios, igarapés ou lagos, localizados próximos ou não das suas moradias. Esta dinâmica de produção é característica de redes de funções das cadeias produtivas, de acordo 
com (NODA et al., 2007, p. 28) de modo que "distribuem-se em diversos níveis de atuação econômica e com uma série de interrelações mantidas entre vários atores sociais". A aproximação entre as áreas de produção e os centros urbanos é muito importante para o escoamento da produção que acontece via fluvial. No entanto, como no caso de Tupi I, que é uma localidade mais distante, tem maior dificuldade de acesso aos centros comerciais e "maiores gastos com o item transporte para a comercialização, constituindo-se um fator de limitação" (NODA et al., 2007, p. 58). Além disso, como verificam Pinton \& Laure (2000, p. 63), a dinâmica da produção na agricultura familiar tem sofrido alterações, entre outras questões, em decorrência também da necessidade de escolarização dos jovens; de modo que reduz a mão de obra familiar, mas exige maior investimento na agricultura para garantir a alimentação dos filhos e filhas e ainda de quem os cuida na cidade onde estudam.

Tupi I certamente tem suas especificidades sociais, mas também revela muitos aspectos da realidade vivenciada pela população amazônica o que nos remete à reflexão de uma maior compreensão da sociodiversidade local em face dos processos contemporâneos.

\section{O conhecer-fazer: uso, manejo e conservação de plantas medicinais}

A ajuda médica que é complicada; tem agente de saúde que recebeu da prefeitura de São Paulo de Olivença uma rabeta para transportar as pessoas da comunidade para Tabatinga. A prefeitura repassa remédio: ass, dipirona, mas de forma insuficiente para distribuir entre todos. Situações graves já ocorreram como mordida de cobra, vez ou outra tem; o outro quebrou os dedos da mão carregando madeira; mais são as crianças que precisam ser levadas. Adulto, nunca teve gente com doença grave, mas já morreu um homem de hepatite, faz tempo. Ai corre para o remédio caseiro, toma os dois, caseiro e de farmácia. Caseiro é mais fácil de conseguir, pois a gente não tem dinheiro para o de farmácia; só se conseguem eles em São Paulo de Olivença ou em Tabatinga. A gente sempre usa remédio caseiro, só não usa quando não precisa. É preferido o remédio caseiro porque é mais fácil de conseguir, pois ninguém tem o dinheiro para o de farmácia. Mas, o de farmácia tem efeito mais rápido. As plantas servem para fazer remédios caseiros e também para banhos; faz quando dá catapora, mas, mais é chá que se far. Faz o chá com as folhas do milho roxo, de tabaco, de goiabeira, da sabugueira, da folha de mata-pasto, essa é boa pra malária. E também tem o chá da casca de pau-urana e da de azeitona. É importante saber das plantas porque no caso não tem o 
medicamento se socorre nas plantas; E, por causa, às vezes, para não gastar dinheiro com doença; A gente tira de casa porque da farmácia tem gasto. E a gente planta a planta que a gente sabe que serve e dá bem. D. Graça tem muitas. A gente consegue algumas plantas em Tabatinga; ensinam que é bom pra alguma doença ou que a gente sabe pra que serve e trazpra plantar. O uso de remédios fabricados a partir de plantas medicinais é concomitante com o uso de remédios de farmácia, o lugar da importância de um e de outro é reservado a diferentes circunstâncias; ora o remédio caseiro por estar mais à mão, ora o remédio de farmácia porque o efeito esperado parece acontecer mais rápido. Assim, ambos têm sua relevância e significados no âmbito social e cultural, o habitus é aliado também a uma estratégia de sobrevivência diante das diversidades do cotidiano, ao lidar, principalmente, com situações de enfermidades.

As plantas medicinais que foram frequentemente as mais referidas para certas enfermidades/doenças são: alfavaca - diarreia/ "doença do ar", algodão roxo - ameba/tosse/cólica; boldo - dor no estômago, coirama tosse/dor de cabeça/gripe; crajiru - "ferida que não sara", japona - gripe/ dor de cabeça; mastruz - dor de estômago/verme; mucuracaá - dor de cabeça, pluma - indigestão, pobre velho - febre/inflamação; sabugueiro - febre/febre com gripe; saratudo - diarreia, trevo roxo - dor de ouvido; vassourinha "espremedeira" / picada de cobra/ dor no corpo. Das enfermidades aparecidas sob nomes como doença do ar, ferida que não sara e espremedeira, é interessante perceber como as especificidades são assim criativas não somente de imaginação, mas, sobretudo, de observação empírica. A doença do ar diz respeito ao que mais comumente é conhecido como "asma"; ferida que não sara é quando se observa o tempo e as dificuldades de um ferimento desaparecer; a espremedeira é o exemplo mais interessante no que tange perceber o imbricado do mágico/ simbólico e real/material do conhecimento tradicional. ... A espremedeira é o que dá na criança pequena, é uma força que parece dar na criança; ai ela fica se espremendo... a gente vê... se não tratar logo, a criança pode ficar com o umbigão. Com o uso de plantas medicinais em Tupi I/SPO, verifica-se uma grande diversidade de espécies bem como as plantas medicinais apresentam uma variedade de uso com relação a tipos de enfermidades. Os usos das plantas medicinais demonstram um grande domínio de conhecimento das possibilidades de eficácia e de sua dimensão mágica, a fé. Ramírez (1996, p. 258) ao pensar na selva amazônica como uma grande planta medicinal compreende "El examen de esa red y su funcionamiento permite finalmente afirmar que la selva no sólo produce 
plantas medicinales sino también cultura y, en particular, cultura de salud". A ideia de uma cultura de saúde amplia o sentido social quanto ao uso de plantas medicinais onde se revela o cuidar das pessoas, de tal maneira que podemos perceber nesse âmbito a dinâmica do metabolismo sociedade/natureza nos conhecimentos tradicionais. Além disso, é de fundamental relevância que os contextos sociais e culturais possam expressar suas próprias necessidades.

Em Tupi I, no que tange às enfermidades, a preocupação é grande em relação à distância de postos de saúde e hospital e as plantas medicinais representam o socorro imediato. Contudo, não somente, posto que apontem os usos das plantas para o tratamento de enfermidades. Assim, o tratamento apresenta um sentido mais abrangente quanto ao seu uso para efetivar a cura. Nos casos de uso da alfavaca que serve pra doença do ar; se cuidar quando é criança, cura. E ainda, no uso do crajiru pra ferida que não sara, fica passando na ferida até ficar boa; do pobre velho que é bom pra inflamação, fica tomando o chá, como tratamento, até ficar boa.

Dentre as espécies usadas, as folhas representam a parte mais utilizada de uma planta medicinal, pois este é um dos aspectos principais do conhecimento de uma planta medicinal. Assim, as folhas são as mais representativas da parte mais utilizada de uma planta medicinal, mas ainda são bastante usadas as raízes e cascas de árvores. As folhas são também as partes da planta pelas quais uma planta medicinal é reconhecida e diferenciada de outras não medicinais. Desse modo, o algodão roxo é diferente do algodão branco porque se observa que a cor da folha do primeiro é em tom roxo e a do segundo é verde. A japona também é diferenciada pela cor da folha, assim tem a japona de folha em tom roxo e a japona de folha verde, essa variedade da cor também é observada no talo (caule) da planta que corresponde à mesma cor da folha. Estas observações, de acordo com Noda e Noda (2003, p. 157) como também, no caso da agricultura, verificase que "os conhecimentos estão relacionados à percepção e domínio sobre as fenofases das plantas: época de floração, frutificação, mudança foliar, além dos diferentes ecossistemas onde ocorrem determinadas espécies de plantas".

O manejo de plantas medicinais ocorre de uma necessidade ou uma ocasião num dado momento específico quando do aparecimento da enfermidade o que justificou conseguir a planta; ou ainda, uma ocasião qualquer em que se visita um parente, amigo, etc. no município sede ou mais próximos. A ocorrência do manejo das plantas ocorre sempre num contexto de uma situação sociocultural, isto é, corroborado pela proveniência das plantas. De 
lugares onde se tem forte relacionamento de parentesco. Assim, tal manejo de uma planta transportada acontece tendo em vista que tal planta sempre é boa para alguma coisa; tendo em vista uma utilidade, mas não tão somente, porque também se maneja a planta para a socialização da mesma; desse modo, é como a expressão é bom ter caso alguém precise ou é bom ter porque pode alguém querer e aí a gente já tem. $\mathrm{O}$ modo como manejam está relacionado com o conhecimento do desenvolvimento vegetativo da planta. São trazidas em galhos que irão brolhar, a técnica de coleta em específico é a de que sabem quais dão de galho e quais não dão; por isso, algumas, é preciso pegar com raiz e tudo, e outras não. Quanto à conservação, não está meramente no fato de que plantam no quintal ou ainda no fato de que, quando no período de cheia, plantam em canoas suspensas, vasos, etc. A conservação ocorre no processo mesmo da experimentação, do conhecimento da natureza em relação ao solo e ao clima - posto que não plantam em qualquer lugar -, da experimentação porque testam no próprio corpo o efeito de certo uso de uma planta, mas, embora às vezes parece estar a fé antes da eficácia fisiológica e, ainda, ocorre no processo de socialização do conhecimento através da dinâmica da estrutura estruturante que permite a outras gerações conhecer e manipulá-las. Destarte, os usos de plantas medicinais representam acontecimentos socioculturais e ocasiões concretas dos modos de existir. Desse modo, ao observarmos os usos de certas plantas por uma determinada população, podemos obter também certa compreensão de que males podem estar sofrendo, bem como, de sua relação saúde/doença. Além disso, a quais aspectos isto pode estar relacionado, qual a frequência das enfermidades, se o poder público está atento às mudanças quanto às necessidades sociais, que tipo de relações culturais as pessoas estabelecem com relação à natureza e com relação ao próprio corpo etc.

Nesse sentido, uma questão de enorme relevância, no que tange compreender a Amazônia nesse contexto, poderia ser revista a partir da riqueza não apenas natural, mas também, social que essa região apresenta; pois é nessa sociodiversidade que as relações do cotidiano revelam estratégias e suas riquezas culturais. Quando grande parte dos conhecimentos tradicionais que manipula a biodiversidade para cuidar da saúde está, em sua maioria, voltado à perspectiva econômica: são os usos das plantas medicinais apropriados transformados em mercadoria e perdem toda uma riqueza de significação sociohistórica muito mais abrangente do cuidar das pessoas que essas culturas de saúde compreendem. 


\section{A tradição e a relação sociedade/natureza}

Ao apreendermos os conhecimentos tradicionais numa dinâmica histórico-cultural, tendo em vista que afirmamos que são permanentes, mas também mudam, isto encerra compreender quais e como os processos sociais são aí estruturas e estruturantes. Nesse sentido, implica o fato de que a tradição que compreendemos é histórica.

É observável, em toda sociedade, um processo histórico-cultural com suas peculiaridades, mas também, semelhanças compartilhadas, ou não, que podem ser verificadas por estudos históricos. É verificável, ainda, que o papel da natureza é diversificado nos modos de apropriação que a sociedade faz dela.

Destarte, a tradição move-se numa trajetória específica. Nesse sentido, cada cultura tem a sua tradição. $O$ que faz todo sentido afirmar da tradição suas peculiaridades inventivas e criativas. E, portanto, podemos afirmar que esta tradição move-se na relação sociedade/natureza como ação social autopermanente e autotransformadora dos conhecimentos locais no modo como fazem usos da natureza. Desse modo, a tradição, num processo histórico-cultural onde se delineia a trajetória da sociedade, diretamente implica na forma como a natureza é apropriada. Mas se afirmamos essa condição em toda sociedade, afirmamos de modo específico que a cultura tradicional é peculiar quanto aos usos da natureza em sua inventividade e criatividade objetiva e subjetiva. Atua sob essa natureza em uma práxis histórico-cultural que está diretamente relacionada a modos de existir específicos, mas que, também, apreende a diversidade natural a partir da diversidade inventiva em que compartilha saberes. Mas, tal compreensão justificaria falar em população tradicional? Ou melhor, de onde vem a noção que uma população é tradicional? Nesse contexto, a noção de populações tradicionais se inserida na conjuntura das questões socioambientais, não nos permite encontrar sua origem, mas antes, uma apropriação para contextos de interesses específicos. E num âmbito mais teórico, a construção do olhar exótico é uma percepção etnocêntrica que se espraia como pensamento hegemônico sob a designação do termo. Contudo, nessa conjuntura, nos interessa antes entender a invenção das tradições.

Como afirma Hobsbawn (1997), as tradições inventadas constituem um amplo sentido de práticas culturais que se perduram, tanto no sentido de realmente inventadas, quanto no de que surgem. Desse modo é possível 
entender uma tradição realmente inventada que se formaliza institucionalmente na trajetória dinâmica de cada cultura e, também, a "tradição inventada", que nem sempre tem um passado tão remoto, mas, que é difícil de localizar numa limitação de tempo. A “tradição inventada" refere-se a um conjunto de práticas, com normas estabelecidas a fim de solidificar certos valores, de modo que sempre busca referências no passado. Este passado histórico apresenta uma significação quase que apenas de artifício e que, de certa forma, é como se o caráter histórico por si só já estabelecesse a relevância de sua continuidade. Como afirma Hobsbawn, uma relação bastante artificial, pois, trata-se de reações a situações novas em que estas ou vão buscar ligações com situações no passado ou criam seu próprio passado. Dessa forma, a tradição não deve ser confundida com os costumes, pois o passado ao qual se refere impõe suas práticas de maneira fixa como repetição. Nesse sentido, o que Hobsbawn se refere como costume na sociedade tradicional (termo do autor) trata-se de práticas que, do mesmo modo, tem por função fixar e também dinamizar; como ele afirma, é "motor e volante", pois permite a mudança, desde que desejada ou como resistência ao novo. De outro modo também, a "tradição inventada" não pode ser confundida com a convenção ou a rotina, pois estas são justificadas de maneira pragmática.

O mais interessante para nós trata-se da distinção da invenção das tradições - como as realmente inventadas onde a história é o contexto imprescindível de seu enredo - e aquelas que não expressam um fato histórico. O autor demonstra, pois, nesta última, tratar-se de uma situação política de reivindicação, por exemplo, de camponeses por "terras ou direitos comuns com base em costumes de tempos imemoriais" (HOBSBAWN, 1997, p. 10), porque a questão em jogo não é a tradição, mas sim, o processo de lutas constantes entre forças de interesses sociais contrários.

Nesse sentido, ao nos reportarmos aos conhecimentos tradicionais nos parece, de maneira clara, que as tradições realmente inventadas e a "tradição inventada", de acordo com a compreensão de Hobsbawn (1997), têm uma relação dialética quanto ao conceito de populações tradicionais. Se, por um lado, como afirmamos, é possível compreender dos conhecimentos tradicionais uma ossatura de construção do conhecimento em que se "processa" sua existência histórico-cultural imprescindível de aspectos simbólicos, por outro, dizer dos seus detentores como populações tradicionais encerra a dimensão das conjunturas políticas e econômicas de nossa contemporaneidade. 
Em torno das questões socioambientais nas quais se põem em pauta (entre outras questões) a problemática da devastação da natureza, a criação de unidades de conservação e preservação - o que implica diretamente a exploração dos recursos naturais -, entra em pauta as populações tradicionais não apenas como cultura tradicional, mas como uma categoria política. Desse modo, nesse contexto, encontram-se e defrontam-se os diferentes interesses entre os diferentes grupos sociais como as quebradeiras de coco de babaçu, seringueiros, pescadores artesanais, quilombolas e povos indígenas, homogeneizados como populações tradicionais (ou povos da floresta, ou comunidades tradicionais) na polarização com grupos de interesses de grande capital. Dentre os fatores e aspectos que decorrem dessa situação, a tradição realmente inventada não é exatamente o foco de tais questões, pois é possível afirmar que processos de legitimação reguladores dos usos da natureza na Amazônia a partir de programas e políticas voltadas para um "desenvolvimento" regional tendem a ignorar o reconhecimento dos conhecimentos tradicionais aqui existentes. Neste sentido, diferentes questões podem ser postas de modo a aproximar análises sobre política, economia e globalização dos saberes locais da Amazônia, de modo ainda a enxergar que as ideias construídas sobre essa região não podem deixar de serem críticas; para tanto, não se pode desconsiderar a pluralidade do conhecer sociocultural amazônico.

O que nos interessa, pois, identificar nesse âmbito, quanto às tradições, é a maneira abrangente de percepção do conceito de populações tradicionais, de maneira crítica, como uma categoria política, sem que isto signifique desconsiderar a cultura. A cultura passa a ser analisada também de maneira crítica, para além da descrição dos costumes e modos de ser das sociedades. Desse modo, se propõe perceber e analisar os conhecimentos tradicionais como uma categoria de análise independente do conceito de populações tradicionais, na medida em que este é fluido no tempo e no contexto social, e, contemporaneamente tem representado visões fetichizadas dos conhecimentos tradicionais, reproduzidas sem uma análise crítica onde são relacionados sentidos e intenções, direitos e distorções nos panoramas para e da Amazônia. Neste âmbito, não é possível desvencilhá-la da dimensão humana onde incidem os processos de transformações externas, mas não sem resposta a estas transformações. Como bem analisa Freitas (2003) em relação às populações ribeirinhas da Amazônia, estas mudam de perfil e estão em permanente construção de sua identidade. Essa dinâmica se constitui, em vários marcos, ao longo de processos históricos de remanejamento social, desde a época colonial até o advento da sociedade nacional, e está relacionada com o 
extrativismo da borracha e com as frentes migratórias, não apenas dirigidas, mas também espontâneas em nossa contemporaneidade. Desse modo, Freitas afirma ainda, que as populações provenientes desses processos sociais, em busca de terra, de um lugar para sobreviver, podem ser consideradas as populações ribeirinhas aqui presentes. Contudo, as políticas de ocupação do território reordenam os espaços e estes passam a se constituir com regras institucionalizadas; assim, "as populações ribeirinhas passaram a ser classificadas em tradicionais e não tradicionais, mas é na dinamicidade desses processos que ela se constitui" (FREITAS, 2003, p. 40). Esta análise nos esclarece o que tange à invenção das tradições no modo como explica Hobsbawn (1997, p. 12) de que novas tradições são inventadas "quando ocorrem transformações suficientemente amplas e rápidas tanto do lado da demanda quanto da oferta". Nesse sentido, é possível perceber a relação dialética entre os processos de institucionalização na Amazônia e as alternativas de sobrevivência da população amazônica; desse modo ainda, a inovação, na tradição, reveste-se de um caráter de antiguidade presente na dinâmica populacional e social na região amazônica.

O que este contexto corrobora para afirmarmos dos conhecimentos tradicionais, sem incorrer no campo fluido do conceito de populações tradicionais, é o aspecto no qual "a força e a adaptabilidade das tradições genuínas" não podem ser confundidas com "a invenção das tradições". "Não é necessário recuperar nem inventar tradições quando os velhos usos ainda se conservam" (HOBSBAWN, 1997, p. 16). Desse modo, a questão dos saberes tradicionais não pode ser apropriada como marketing sobre o uso de recursos naturais na Amazônia em face do desenvolvimento sustentável, pois, percebêlos enquanto uma ossatura de construção de conhecimento na e da região Amazônia encerra um olhar crítico sobre os processos que a redesenham em nossa contemporaneidade. Este é um aspecto no contexto em que Freitas (2003) afirma, ainda, que a crítica ao conceito de desenvolvimento sustentável deve ser feita não apenas na academia, mas, sobretudo, pelas populações aí envolvidas, posto que precisam ser instrumentalizadas quanto "às noções que o pensamento científico difunde ou que as ideologias ambientalistas difundem" para que possam distinguir as feições que se delineiam em torno do desenvolvimento sustentável, de uso racional da floresta, de áreas protegidas, etc.; do contrário, serão convencidas sem uma visão crítica "de que a ética seria a solução". A compreensão da diversidade dos modos de existir da vida amazônica requer perceber que agricultores, pescadores, índios, ribeirinhos, 
comunidades extrativistas "não podem condenar-se a si próprios a se confundirem com as árvores ou com os recursos, porque são atores humanos, e enquanto atores humanos são históricos e capazes de decidir" (FREITAS, 2003, p. 43 e ss.). Esta análise apreende justamente uma atitude política, ou melhor, a práxis política em relação ao uso da natureza, o que inclui a terra como território, em que as populações amazônicas devem estar inseridas, munidas não apenas de suas vivências, mas de suas condições críticas.

Marx (1991), ao estudar a relação sociedade/natureza, suas condições de produção e reprodução da vida social em diferentes comunidades pré-capitalistas, demonstra que elas não representam meramente um produto 'de fato' da bistória, mas corresponde a uma realidade da qual homens e mulheres "têm consciência como tal". Esta compreensão encerra uma origem, no sentido de que se tem a condição prévia da "propriedade da terra" na qual a relação é a do "sujeito que trabalha com as condições naturais de seu trabalho como algo que lhe pertence" (MARX, 1991, p. 70 e ss.). Para além das questões que encerram esta apreensão e em torno das quais o autor discorre sua análise, nos interessa perceber dessa ótica o aspecto de pertencimento no qual os sujeitos se ligam à terra, porque nela trabalham e garantem a sobrevivência. Mas, não apenas a própria sobrevivência é evidenciada, posto que a existência da própria comunidade depende da "manutenção da igualdade" entre todos autossuficientes bem como do trabalho individual "como condição da persistência" da propriedade. Desse modo, nos interessa perceber, ainda, que os modos de existir na Amazônia têm suas condições de persistir onde a tradição não representa apenas o aspecto simbólico porque agrupa e sustenta a sobrevivência. Mas, como também demonstra Marx, num aspecto de evolução que as mantêm é "a reprodução das relações entre o indivíduo e sua comunidade aceitas como dadas", "mais ou menos produtos da história", digamos, por fim, dinâmicas no contexto social, "porém fixadas na tradição" (MARX, 1991, p. 79). Assim, a conectividade da relação social para com a natureza no que tange à tradição, como vimos, não prescinde do fato de que novos elementos são apropriados em variados sentidos, portanto, também os usos sociais da natureza.

\section{Considerações Finais}

A dimensão prática dos conhecimentos tradicionais é indissociável de uma dimensão reflexiva que apreende um sistema simbólico criado e recriado 
dialeticamente nas relações sociais históricas para com a natureza, onde o conhecimento sobre ela é aprimorado. Destarte, compreendemos desse modo um conhecer-fazer que confere a força do habitus quanto aos conhecimentos de plantas medicinais adquiridos e socializados. O que esta dimensão da vida social interessa no âmbito das realidades amazônicas é no sentido, posto aqui, da formação social dos conhecimentos tradicionais da Amazônia a partir de uma racionalidade subjacente às práticas de uso, manejo e conservação das plantas medicinais no que tange, ainda, a seus modos de existir.

Assim, no processo em que se dá/ocorre o acesso e a apropriação desse recurso observa-se um procedimento de uma prática de aperfeiçoamento de observação empírica de apropriação do mundo natural, do mesmo modo que se pode dizer de um aperfeiçoamento reflexivo porque estrutura mentalmente suas práticas de uso. Na medida em que a compreensão dos conhecimentos tradicionais como uma ossatura de construção do conhecimento revela uma visão de mundo integradora do mundo natural e do mundo social num contexto histórico o qual constantemente se remete ao passado, é vivido no momento presente, metamorfoseando-se nos encontros culturais, e é valorizado no devenir histórico.

Ao percebermos os saberes tradicionais enquanto construção de conhecimento desvela-se o domínio de um conhecimento estruturante porque estruturado. A partir desta ótica, a cultura não se trata de um processo tão somente de inculcar significados/significantes como estrutura estruturada; a dimensão simbólica é apreendida no contexto das condições materiais de existência; a dinâmica cultural, pois, é imanente dessa realidade social, assim sendo se tem que os conhecimentos tradicionais se apresentam também enquanto estruturas e práticas - um conhecer-fazer. Formas de perceber e se relacionar com a natureza as quais se estabelecem ao mesmo tempo em que se redefine constantemente, justamente porque o perceber e se relacionar com a natureza é um processo sociocultural e histórico bem como se volta a si mesmo no como perceber e se relacionar. Confere, pois, o duplo processo de interiorização da exterioridade e de exteriorização da interioridade (BOURDIEU apud MICELI, 2004), de maneira como se percebe aí também a construção do conhecimento, como afirmamos, na dimensão reflexiva/prática da e na vida social. Nesse sentido, a praticidade quanto aos usos da natureza torna objetiva com a ação o que lhe é anteriormente imanente. Destarte, a prática é resultante de um processo relacional dialético entre uma estrutura e uma conjuntura (MICELI, 2004, p. 40) que sempre se renova; apreende-se, portanto, uma relação entre estruturas, 
habitus e práticas o que estabelece a permanência bem como, a mudança dos conhecimentos tradicionais de plantas medicinais.

\section{Nota}

1. Os depoimentos dos moradores e moradoras de Tupi I/São Paulo de Olivença/ Amazonas ocorreram em setembro e outubro de 2007.

\section{Referências}

ENCICLOPÉDIA DOS MUNICÍPIOS BRASILEIROS. Planejada e orientada por Jurandy Pires Ferreira, presidente do Instituto Brasileiro de Geografia e Estatística. Responsabilidade do Conselho Nacional de Geografia. Editado em 21 de outubro de 1957.

FREITAS, Marilene Corrêa da Silva. Entrevista. A natureza humanizada é muito mais justa que a natureza bruta. In.: Cadernos do Ceas. Centro de Estudos e Ação Social. Salvador: Ceas, setembro/outubro, n. ${ }^{\circ}$ 207, 2003.

HOBSBAWN, Eric; RANGER, Terence. A invenção das tradições. São Paulo: Paz e Terra, 1997.

MARX, Karl. Formações econômicas pré-capitalistas. Introdução de Eric Hobsbawm. Tradução de João Maia. São Paulo: Paz e Terra, 1991.

MICELI, Sérgio. Introdução: a força do sentido. In: BOURDIEU, P. A economia das trocas simbólicas. São Paulo: Perspectiva, 2004.

NODA; NODA. Agricultura familiar tradicional e conservação da sociobiodiversidade amazônica. Revista Internacional de Desenvolvimento Local, v. 4, n. 6, mar., 2003.

NODA, Sandra do N.; MARTINS, Ayrton Luiz; NODA Hiroshi et al., Contexto socioeconômico da agricultura familiar nas várzeas da Amazônia. In: NODA, Sandra (org.). Agricultura familiar na Amaẑninia das Águas. Manaus: Editora da Universidade Federal do Amazonas, 2007. 
PINTON, Florence; EMPERAIRE, Laure. A farinha de mandioca, um elo dos sistemas extrativistas. In: EMPERAIRE, Laure (org.). A floresta em jogo: o extrativismo na Amazônia Central. São Paulo: Editora Unesp, Imprensa Oficial do Estado, 2000.

RAMÍREZ, Germán Zuluaga. La Selva: Una Gran Planta Medicinal. In: PAVAN, Crodowaldo (org.). Uma estratégia latino-americana para a Amazônia. Brasília: Min. do Meio Amb. dos Rec. Hídricos e da Amaz. Legal; São Paulo: Memorial, 1996. 